\title{
Degradation Performance of Open-Cell Biomaterials from Phosphated Carbonyl Iron Powder with PEG Coating
}

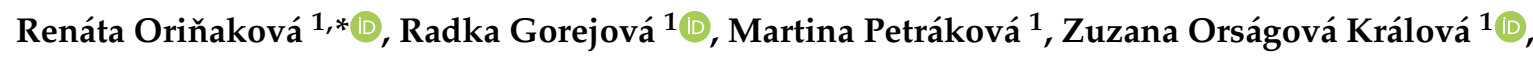 \\ Andrej Oriňak ${ }^{1}$, Miriam Kupková ${ }^{2}$, Monika Hrubovčáková ${ }^{2} \mathbb{D}$, Mária Podobová ${ }^{2}$, \\ Matej Baláž ${ }^{3}$ (D) and Roger M. Smith ${ }^{4}$ (D) \\ 1 Department of Physical Chemistry, Faculty of Science, Pavol Jozef Šafárik University in Košice, \\ Moyzesova 11, 041-54 Košice, Slovakia; radka.gorejova@student.upjs.sk (R.G.); \\ martina.petrakova@student.upjs.sk (M.P.); zuzana.orsagova.kralova@upjs.sk (Z.O.K.); \\ andrej.orinak@upjs.sk (A.O.) \\ 2 Institute of Materials Research, Slovak Academy of Sciences, Watsonova 47, 040-01 Košice, Slovakia; \\ mkupkova@saske.sk (M.K.); mhrubovcakova@saske.sk (M.H.); mpodobova@saske.sk (M.P.) \\ 3 Institute of Geotechnics, Slovak Academy of Sciences, Watsonova 45, 040-01 Košice, Slovakia; \\ balazm@saske.sk \\ 4 Department of Chemistry, Loughborough University, Loughborough, Leicestershire LE11-3TU, UK; \\ r.m.smith@lboro.ac.uk \\ * Correspondence: renata.orinakova@upjs.sk; Tel.: +421-55234-2324
}

Received: 14 August 2020; Accepted: 15 September 2020; Published: 17 September 2020

check for updates

\begin{abstract}
Advances in biomedicine and development of modern technologies in the last century have fostered the improvement in human longevity and well-being. This progress simultaneously initiated the need for novel biomaterials. Recently, degradable metallic biomaterials have attracted serious attention in scientific and clinical research owing to their utilization in some specific applications. This work investigates the effect of the polyethylene glycol (PEG) coating of open-cell iron and phosphorus/iron foams on their microstructure and corrosion properties. The addition of phosphorus causes a slight increase in pore size and the deposition of a polymer coating results in a smoothened surface and a moderate decrease in pore diameter. The PEG coating leads to an increase in corrosion rates in both foams and potentially a more desirable product.
\end{abstract}

Keywords: degradable biomaterials; iron; phosphated iron; corrosion behavior; microstructure

\section{Introduction}

The massive evolution of novel technologies enabling the production of advanced biomedical devices with higher clinical performance in the last decades has brought increased living standards and life expectancy [1-3]. In addition to permanent medical implants, biodegradable materials have gained substantial interest from the material engineering and medical communities. Temporary intervention is desirable in some specific orthopedic, cardiovascular, and pediatric applications. Biodegradable materials can avoid the negative effects associated with long-term implants, for instance, stress shielding, inflammation, thrombus formation, migration of the implant, and re-intervention to remove devices with a transient function [4-9]. Degradable biomaterials represent the next generation of highly bioactive materials, which are envisaged to facilitate the restoration of diseased tissue and thereafter naturally decompose in the human body environment without leaving toxic degradation products, to be replaced by healing tissue [2,6,10-13]. In orthopedic applications, the degradation rate of an implant should be consistent with the rate of bone tissue 
reconstruction to maintain the mechanical integrity and to enable a progressive transfer of load to the rebuilding bone. Moreover, the degradation kinetics should be appropriate to prevent an intolerable local or systemic accumulation of degradation products [6,10,11,14-16].

Among the three principal bioresorbable metallic elements $(\mathrm{Mg}, \mathrm{Fe}$, and $\mathrm{Zn})$, iron and its alloys have received attention as temporary orthopedic implant materials, particularly in appliances necessitating the extensive mechanical support in the course of the bone repairing process $[4,6,10,17,18]$. Good biosafety and biocompatibility of pure iron have been demonstrated in in vitro and in vivo studies [4,18-21]. The main drawback of Fe-based materials is that the degradation rate is usually too slow in physiological environments owing to the deposition of the dense film of corrosion products passivizing the surface $[4-6,10,14,17,18]$. Alloying elements, such as $\mathrm{Mn}, \mathrm{C}, \mathrm{Si}$, and Pd, increase the degradation rate of iron, but at higher concentrations could cause a potentially toxic effect $[4,6]$. An alternative strategy to improve the kinetics of iron corrosion is modification of the surface and/or structure.

Recently, network-like metal foams $[6,17,22,23]$, including open-cell iron foams $[9,11,18]$, have been identified as promising materials for hard tissue scaffolds as they exhibit a natural bone-like structure, which supports the vascularization, growth, and proliferation of bone cells and reduces corrosion resistance $[6,17,18,22,24]$. The improvement of the mechanical strength of iron foams can be achieved by the addition of low amounts of phosphorus without retarding the corrosion rate or affecting the cell proliferation [11,14].

The application of biodegradable polymer coatings such as polyethylene glycol (PEG) and poly(lactic-co-glycolic acid) (PLGA) on iron foams represents a new concept to improve the degradation behavior [18]. The local acidity on the iron surface generated by hydrolysis or oxidation of the polymers appears to enhance the degradation process and biocompatibility $[18,25,26]$. In an earlier paper, we reported that the degradation rate of coated iron foams increased with increasing thicknesses of the PEG layer [25], and in this work, we have set out to extend this study to a thicker PEG coating layer and to include both $\mathrm{Fe}$ and $\mathrm{Fe}$-phosphorus $(\mathrm{Fe} / \mathrm{P})$ foams. Immersion corrosion tests and potentiodynamic polarization corrosion tests were carried out to study the effect of a thicker PEG layer on degradation rate. Electrochemical impedance spectroscopy (EIS) was selected to identify the interfacial properties of uncoated and coated $\mathrm{Fe}$ and $\mathrm{Fe} / \mathrm{P}$ foams and to investigate in detail the degradation process after the foams were exposed to a simulated body fluid.

\section{Materials and Methods}

\subsection{Fe Foam Preparation}

Carbonyl iron powder (CIP) purchased from BASF (type CC d50 3.8-5.3 $\mu \mathrm{m}$, Ludwigshafen, Germany) was utilized as raw material. The chemical composition of CIP was: minimum (min.) $99.5 \%$ $\mathrm{Fe}$, maximum (max.) $0.18-0.35 \% \mathrm{O}$, max. $0.05 \% \mathrm{C}$, and max. $0.01 \% \mathrm{~N}$. Iron foams were manufactured by replication method using polyurethane foam (PUR) (Filtren ${ }^{\circledR}$ TM 25133 with the cell size 1060-1600 $\mu \mathrm{m}$, Eurofoam, Brno, Czech Republic). The cylindrical specimens (Ø $10 \mathrm{~mm}, \mathrm{~h} 20 \mathrm{~mm}$ ) were cut out from PUR and impregnated with a suspension consisting of $7 \mathrm{~g}$ of CIP and $200 \mathrm{mg}$ of gelatin (Sigma-Aldrich, Saint-Louis, MO, USA) in $6 \mathrm{~mL}$ of water at $60^{\circ} \mathrm{C}$. The impregnation of PUR foam was conducted for a period of $24 \mathrm{~h}$. Thereafter, the sintering of impregnated cylinders was performed in a tube furnace Aneta 1 (ANETA, Trenčianská Teplá, Slovakia) at $450{ }^{\circ} \mathrm{C}$ for $2 \mathrm{~h}$ in nitrogen atmosphere to thermally remove the PUR template. The resultant iron foam was produced after subsequent sintering at $1120^{\circ} \mathrm{C}$ for $1 \mathrm{~h}$ in a reduction atmosphere $\left(90 \% \mathrm{~N}_{2}, 10 \% \mathrm{H}_{2}\right)$.

\subsection{Fe/P Foam Preparation}

To obtain the iron-phosphate-coated carbonyl iron powder (Fe/P), a modified precipitation method was applied. The phosphating process was realized by stirring the iron powder in a solution containing acetone and orthophosphoric acid (acetone: $\mathrm{H}_{3} \mathrm{PO}_{4}$ molar ratio of 1:9) for $2 \mathrm{~h}$ at room temperature. 
After that, the phosphated iron powder was dried at $60^{\circ} \mathrm{C}$ for $2 \mathrm{~h}$ and calcined at $400{ }^{\circ} \mathrm{C}$ in air for $3 \mathrm{~h}$. The Fe/P foams were then prepared by the same procedure as Fe foams but to avoid liquid-phase sintering, the Fe/P samples were heat-treated at $1050{ }^{\circ} \mathrm{C}$. The final Fe/P foams contained $\sim 0.5 \mathrm{wt} . \%$ of phosphorus. The Fe/P material produced by phosphating comprised of globular iron $(\alpha$-Fe phase) and iron oxide particles, embosomed with a solidified liquid phase consisting of ferric phosphate compounds formed during eutectic reactions in the $\mathrm{Fe}_{2} \mathrm{O}_{3}-\mathrm{P}_{2} \mathrm{O}_{5}$ system [27].

\subsection{Preparation of Polymer Coating Layer}

Coating of Fe and Fe/P foams with polyethylene glycol 4000 (PEG) (Sigma-Aldrich, Saint-Louis, MO, USA) was performed through a sol-gel process. Firstly, a $10 \mathrm{wt} \%$ solution of PEG in $96 \%$ ethanol (Mikrochem spol. s.r.o., Pezinok, Slovakia) was prepared and held at ambient temperature for $24 \mathrm{~h}$. Then, the foam samples were cleaned by using ultrasound (in acetone, ethanol, and distilled water for $10 \mathrm{~min}$ each) and dipped into the PEG solution for $3 \mathrm{~h}$ at room temperature, and thereafter, dried for $3 \mathrm{~h}$ at $45^{\circ} \mathrm{C}$. To obtain a thicker polymer coating layer compared to earlier work [25], this sol-gel procedure was repeated 3 times.

\subsection{Material Characterization}

The surface appearance and microstructure of the foams was visualized by a scanning electron microscope (SEM) equipped with an energy dispersive spectrometer (EDX) (JEOL JSM-7000F, Tokyo, Japan with EDX INCA).

To determine the specific surface area $\left(S_{B E T}\right)$ of the specimens, a low-temperature nitrogen adsorption method using a NOVA 1200e Surface Area and Pore Size Analyzer (Quantachrome Instruments, Hartley Wintney, UK) was applied. The Brunauer-Emmett-Teller (BET) theory was used to calculate the $S_{B E T}$ values.

The FTIR spectra were collected with a Tensor 29 infrared spectrometer (Bruker, Karlsruhe, Germany) using the ATR method in the wavenumber range between 4000 and $650 \mathrm{~cm}^{-1}$.

The thermal decomposition of foams was analyzed using a thermogravimetry and differential scanning calorimetry (DSC/TG, JUPITER STA 449-F1 NETZSCH, Selb, Germany) in inert argon atmosphere with a heating rate of $5^{\circ} \mathrm{C} \cdot \mathrm{min}^{-1}$, up to $1120^{\circ} \mathrm{C}$.

The theoretical sintered density $\left(\rho_{T}\right)$ and total porosity $(\pi)$ of the foams were estimated using gravimetry. To prevent penetration of open pores, the foams were encased in Parafilm and sequentially weighted in air and water at room temperature. The Archimedes' principle (DIN ISO3369) was used to determine the density from the following equation [28,29]:

$$
\rho_{T}=\frac{m_{i}}{\frac{m_{P A}-m_{P W}}{\rho_{W}}-\frac{m_{P A}-m_{i}}{\rho_{P}}}
$$

where $m_{i}, m_{P A}$, and $m_{P W}$ are the initial mass $(\mathrm{g})$, mass of the foam encased in Parafilm determined in air $(\mathrm{g})$, and mass of the foam encased in Parafilm determined in water $(\mathrm{g})$, and $\rho_{W}$ and $\rho_{P}$ are the density $\left(\mathrm{g} \mathrm{cm}^{-3}\right)$ of water and Parafilm.

To calculate the total porosity, the weighting of the foam samples was carried out in air and water after vacuum impregnation with benzyl alcohol. The porosity was determined from the following equation [29]:

$$
\pi=\left(1-\frac{m_{i}}{\left(m_{B A}-m_{B W}\right) \cdot \rho_{T}}\right) \times 100 \%
$$

where $m_{i}, m_{B A}$, and $m_{B W}$ are the initial mass $(\mathrm{g})$, mass of the foam impregnated with benzyl alcohol determined in air $(\mathrm{g})$, and mass of the foam impregnated with benzyl alcohol determined in water $(\mathrm{g})$, and $\rho_{\mathrm{T}}$ is the theoretical density of foam $\left(\mathrm{g} \cdot \mathrm{cm}^{-3}\right)$. 


\subsection{Electrochemical Corrosion Test}

Electrochemical corrosion studies were performed using an Autolab PGSTAT 302N potentiostat (Metrohm, Herisau, Switzerland). A standard three-electrode electrochemical cell consisted of an iron-based sample as the working electrode, an $\mathrm{Ag} / \mathrm{AgCl} / \mathrm{KCl}\left(3 \mathrm{~mol} \cdot \mathrm{L}^{-1}\right)$ reference electrode, and a Pt counter electrode. All experiments were carried out with the Hanks' solution ( $\mathrm{pH} 7.4$; $37 \pm 2{ }^{\circ} \mathrm{C}$ ) consisting of $8 \mathrm{~g} \cdot \mathrm{L}^{-1} \mathrm{NaCl}, 0.4 \mathrm{~g} \cdot \mathrm{L}^{-1} \mathrm{KCl}, 0.14 \mathrm{~g} \cdot \mathrm{L}^{-1} \mathrm{CaCl}_{2}, 0.06 \mathrm{~g} \cdot \mathrm{L}^{-1} \mathrm{MgSO}_{4} \cdot 7 \mathrm{H}_{2} \mathrm{O}$, $0.06 \mathrm{~g} \cdot \mathrm{L}^{-1} \mathrm{NaH}_{2} \mathrm{PO}_{4} \cdot \mathrm{H}_{2} \mathrm{O}, 0.35 \mathrm{~g} \cdot \mathrm{L}^{-1} \mathrm{NaHCO}_{3}, 1.00 \mathrm{~g} \cdot \mathrm{L}^{-1}$ Glucose, $0.60 \mathrm{~g} \cdot \mathrm{L}^{-1} \mathrm{KH}_{2} \mathrm{PO}_{4}$, and $0.10 \mathrm{~g} \cdot \mathrm{L}^{-1}$ $\mathrm{MgCl}_{2} \cdot 6 \mathrm{H}_{2} \mathrm{O}$ as the simulated body liquid electrolyte.

\subsubsection{Potentiodynamic Polarization Tests}

The potentiodynamic polarization curves were obtained by varying the applied potential from -400 to $-900 \mathrm{mV}$ (vs. $\left.\mathrm{Ag} / \mathrm{AgCl} / \mathrm{KCl}\left(3 \mathrm{~mol} \cdot \mathrm{L}^{-1}\right)\right)$ at a scanning rate of $0.1 \mathrm{mV} \cdot \mathrm{s}^{-1}$. The corrosion rate $\left(C R\right.$ in $\left.\mathrm{mm} \cdot \mathrm{year}^{-1}\right)$ was calculated in terms of the corrosion current density $\left(j_{\text {corr }}\right.$ in $\left.\mu \mathrm{A} \cdot \mathrm{cm}^{-2}\right)$ from Equation (3) in accordance with ASTM G59 [30]:

$$
C R=\frac{j_{\text {corr }} K E W}{\rho}
$$

where $\rho$ is the density $\left(\mathrm{g} \cdot \mathrm{cm}^{-3}\right), \mathrm{K}$ is a constant, which assigns the units for the corrosion rate $\left(3.27 \times 10^{-3}\right.$

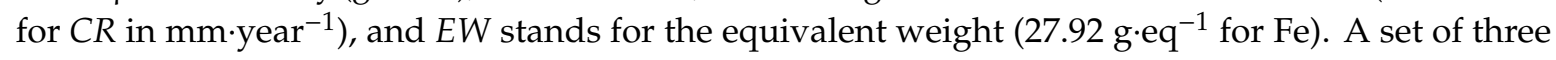
samples was used in each test.

The corrosion current densities $\left(j_{\text {corr }}\right)$, corrosion potentials $\left(E_{\text {corr }}\right)$, and corrosion rates $(C R)$ were determined by applying the simplified Tafel extrapolation method. For all the potentiodynamic polarization measurements, a delay time of $60 \mathrm{~min}$ was set up until the stabilization of the free corrosion potential was achieved.

\subsubsection{Electrochemical Impedance Spectroscopy}

For the electrochemical impedance spectroscopy (EIS) measurements, the applied frequency range was from $10 \mathrm{mHz}$ to $100 \mathrm{kHz}$ and an alternating current amplitude was $\pm 10 \mathrm{mV}$. EIS measurements were performed in the potentiostatic mode at a fixed DC potential, which was set at the open circuit potential (OCP).

\subsection{Immersion Corrosion Test}

Before the immersion degradation test, the initial weights of the foams were determined and the samples were cleaned using the ultrasound in acetone and ethanol for $10 \mathrm{~min}$ each. Cleaned samples were immersed in $100 \mathrm{~mL}$ of the Hanks' solution for 4,8 , and 12 weeks at $37 \pm 1^{\circ} \mathrm{C}$. After the given time of exposure, the samples were removed from the corrosion medium, thoroughly rinsed in water, cleaned using the ultrasound in ethanol for $10 \mathrm{~min}$, and dried. The mass of dried specimens was determined on an analytical balance. The corrosion rate (CR in $\mathrm{mm} / \mathrm{year}$ ) was calculated in terms of mass loss from the Formula (4) in accordance with ASTM G31 standard [31]:

$$
C R=\frac{8.76 \times 10^{4}\left(m_{i}-m_{f}\right)}{\rho A t}
$$

where $m_{i}$ and $m_{f}$ are the initial mass (g) and final mass after immersion $(\mathrm{g}), \rho$ represents the density $\left(\mathrm{g} \cdot \mathrm{cm}^{-3}\right), t$ is the immersion time (hour), and $A$ is the exposed surface area of the sample $\left(\mathrm{cm}^{2}\right)$.

\section{Results and Discussion}

Open-cell Fe and Fe/P foams, prepared using previously reported methods [25,27] and coated with a thicker PEG layer compared to our earlier study [25], were examined. The densities of the Fe, 
Fe-PEG, Fe/P, and Fe/P-PEG foams were $0.72 \pm 0.03 \mathrm{~g} \cdot \mathrm{cm}^{-3}, 0.95 \pm 0.04 \mathrm{~g} \cdot \mathrm{cm}^{-3}, 0.81 \pm 0.05 \mathrm{~g} \cdot \mathrm{cm}^{-3}$, and $0.97 \pm 0.03 \mathrm{~g} \cdot \mathrm{cm}^{-3}$, respectively. The amounts of the polymer deposited onto the surface of the Fe and $\mathrm{Fe} / \mathrm{P}$ foams, calculated from the differences in weight of foams before and after the coating layer deposition, were $\sim 8.5 \mathrm{wt} . \%$ and $\sim 8.2 \mathrm{wt} . \%$ for the Fe-PEG and Fe/P-PEG samples respectively, higher than the previous samples of $0.8-3$ wt. $\%$ [25,26,28]. The porosities were $85 \%, 78 \%, 80 \%$, and $76 \%$, for Fe, Fe-PEG, Fe/P, and Fe/P-PEG foams, respectively. The values of density, porosity, and macropore diameter are summarized in Table 1.

Table 1. Density $(\rho)$, total $\left(\pi_{T}\right)$, open $\left(\pi_{O}\right)$ and closed porosity $\left(\pi_{C}\right)$, and pore size (PS) of iron-based foams.

\begin{tabular}{|c|c|c|c|c|c|}
\hline Sample & $\rho\left(\mathrm{g} \cdot \mathrm{cm}^{-3}\right)$ & $\pi_{T}(\%)$ & $\pi_{O}(\%)$ & $\pi_{C}(\%)$ & PS $(\mu \mathrm{m})$ \\
\hline $\mathrm{Fe}$ & 0.72 & 85 & 80 & 5 & 400-1500 \\
\hline Fe-PEG & 0.95 & 73 & 61 & 12 & 350-1000 \\
\hline $\mathrm{Fe} / \mathrm{P}$ & 0.81 & 80 & 74 & 6 & $400-1700$ \\
\hline Fe/P-PEG & 0.97 & 70 & 61 & 9 & $350-1100$ \\
\hline
\end{tabular}

\subsection{Surface Morphology and Composition}

The SEM micrographs of the surface of iron-based foams are shown in Figure 1 together with details of the surface in secondary electrons (SEI) and backscatter electrons (BSE) (COMPO) imaging regimes.

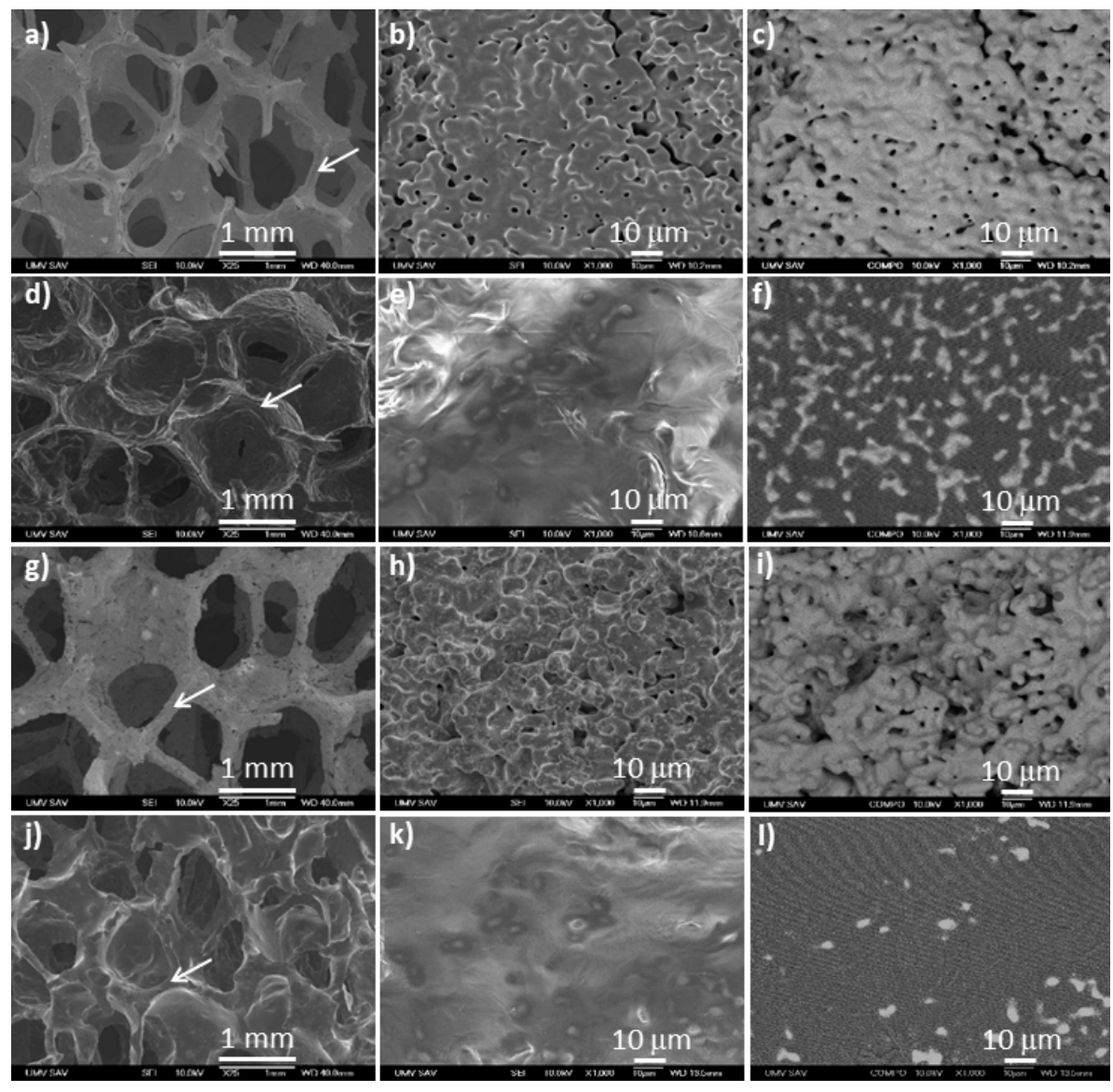

Figure 1. Scanning electron microscope (SEM) micrographs of the surface of iron-based foams: Fe sample $(\mathbf{a}, \mathbf{b}, \mathbf{c})$, Fe-PEG (d,e,f), Fe/P ( $\mathbf{g}, \mathbf{h}, \mathbf{i})$, and Fe/P-PEG (j, $\mathbf{k}, \mathbf{l})$. Magnification: $25 \times(\mathbf{a}, \mathbf{d}, \mathbf{g}, \mathbf{j})$, $1000 \times(\mathbf{b}, \mathbf{e}, \mathbf{h}, \mathbf{k})$, and $1000 \times$ COMPO mode $(\mathbf{c}, \mathbf{f}, \mathbf{i}, \mathbf{l})$. 
The arrows in Figure $1 \mathrm{a}, \mathrm{d}, \mathrm{g}, \mathrm{j}$ indicate the positions of the higher magnification images. The micrographs showed spherical micropores (up to $5 \mu \mathrm{m}$ ) and macropores (from 400 to $1500 \mu \mathrm{m}$ ) in the structure of sintered foams (25×, Figure 1). While phosphating resulted in a moderate increase in pore size as compared to pure Fe, the PEG coating layer partially filled up the pores on the surface of both Fe and Fe/P samples. The small nodes observed on the surface of Fe and Fe/P samples were covered by the polymeric layer, resulting in a smoothened appearance of the coated samples. This was also reflected in slightly lower values of the specific surface areas $\left(S_{B E T}\right)$ of $0.40 \pm 0.08 \mathrm{~m}^{2} \cdot \mathrm{g}^{-1}$ and $0.44 \pm 0.06 \mathrm{~m}^{2} \cdot \mathrm{g}^{-1}$ for the Fe-PEG and Fe/P-PEG foams compared to $0.48 \pm 0.05 \mathrm{~m}^{2} \cdot \mathrm{g}^{-1}$ and $0.50 \pm 0.07 \mathrm{~m}^{2} \cdot \mathrm{g}^{-1}$ for Fe and $\mathrm{Fe} / \mathrm{P}$ samples, respectively.

Higher magnification images of the coated samples revealed that the PEG layer leaked into the pores and flattened the surface roughness $(1000 \times$, Figure 1e,k). Also, the COMPO images indicated only isolated islands of Fe (light grey) on the surface of the coated samples protruding from the polymer (dark grey), in contrast to the surface of the uncoated samples which were mainly composed of Fe. Further evidence of the presence of the PEG coating layer was provided by the EDX analysis of the chemical composition of the surface of the sintered samples (Table 2). Carbon and oxygen arising from the PEG layer were detected on the superficial area of the coated foams. The low content of Fe on the surface of these coated samples corresponded to the tips of Fe nodes protruding from the PEG layer.

Table 2. Chemical composition of the surface of sintered iron-based foams determined from energy dispersive spectroscopy (EDX) analysis.

\begin{tabular}{ccccc}
\hline \multirow{2}{*}{ Sample } & \multicolumn{4}{c}{ Chemical Composition (wt.\%) } \\
\cline { 2 - 5 } & Fe & C & O & P \\
\hline Fe & 100 & 0 & 0 & 0 \\
Fe-PEG & 25.51 & 46.12 & 28.37 & 0 \\
Fe/P & 99.53 & 0 & 0 & 0.47 \\
Fe/P-PEG & 5.38 & 53.87 & 40.75 & 0 \\
\hline
\end{tabular}

\subsection{Thermogravimetric Analysis}

Another evidence of polymer layer presence on the surface of $\mathrm{Fe}$ and $\mathrm{Fe} / \mathrm{P}$ foams was provided by thermogravimetric analysis. The mass loss and phase transformation according to the DSC/TG measurement of Fe and Fe/P foam without PEG (Figure 2a) as compared to foams with a PEG coating layer (Figure 2b) was evaluated.
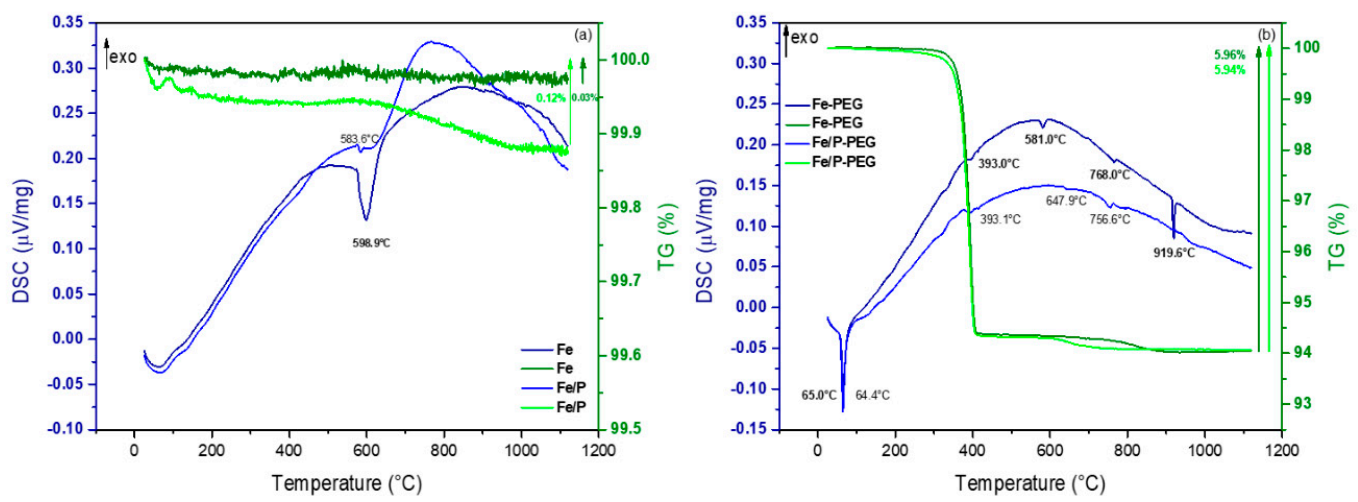

Figure 2. Differential scanning calorimetry/thermogravimetry (DSC/TG) analysis of Fe and Fe/P foams without PEG (a) and with a PEG coating layer $(\mathbf{b})$.

The DSC/TG results for Fe and Fe/P foam without PEG showed visible peaks, particularly some ongoing endothermic reactions, not causing a significant mass loss, mainly in the $\alpha$-Fe region (Figure 2a). Behavior of foam samples with a PEG layer during heating is quite different. Even though there is an 
endothermic peak for Fe foam at $598.9^{\circ} \mathrm{C}$ and Fe-PEG foam at $581.0^{\circ} \mathrm{C}$, which are quite close to one another, in the case of the Fe/PEG sample, the mass loss was much higher, approximately $5.9 \%$ until the plateau is reached. We can see a similar course of curves accompanied by a significant mass loss in the case of Fe/P and Fe/P-PEG foam samples. This mass loss can be influenced by PEG decomposition. Thermal degradation of PEG started at temperature $65.0^{\circ} \mathrm{C}$ for Fe-PEG and $64.4{ }^{\circ} \mathrm{C}$ for Fe/P-PEG, corresponding to the endothermic peak, which can represent the melting temperature of PEG 4000 and is related to the mass decrease with the end of this process at about $400{ }^{\circ} \mathrm{C}$, as mentioned in Kou et al. [32]. It can be seen from TG curves that the decomposition of PEG proceeds in a single step, which is in line with results of Pielichowski et al. [33] and Han et al. [34].

The next peak at $581.0^{\circ} \mathrm{C}$ for Fe-PEG foam and at $647.9^{\circ} \mathrm{C}$ for Fe/P-PEG foam can be related to some chemical reactions between $\alpha$-Fe and products from PEG decomposition. At a temperature of $768{ }^{\circ} \mathrm{C}$ (see peak for Fe-PEG foam), iron has a so-called Curie temperature, which means that it no longer exhibits ferromagnetic properties. This is an example of a phase transition. The last significant peak at $919.6{ }^{\circ} \mathrm{C}$ (Fe-PEG foam) is a phase transformation from $\alpha$-Fe to $\gamma$-Fe. In case of the Fe/P-PEG sample, the peaks are shifted towards lower temperatures as compared to the Fe-PEG sample, probably due to the presence of phosphorus from phosphating.

\subsection{Immersion Corrosion Behavior}

Mass losses of the studied iron-based foams after immersion in Hanks' solution during 4, 8, and 12 weeks are displayed in Figure 3. It is notable that mass losses are significantly greater (about 2 times) for foams with a PEG layer as compared to those without a polymer coating. The lowest weight changes were registered for Fe/P foam. However, the difference between mass loss of Fe and $\mathrm{Fe} / \mathrm{P}$ foam decreased with extension of immersion time. This indicated the higher stability of $\mathrm{Fe} / \mathrm{P}$ foam in the initial period of corrosion due to the presence of phosphate compounds at the surface of iron particles.

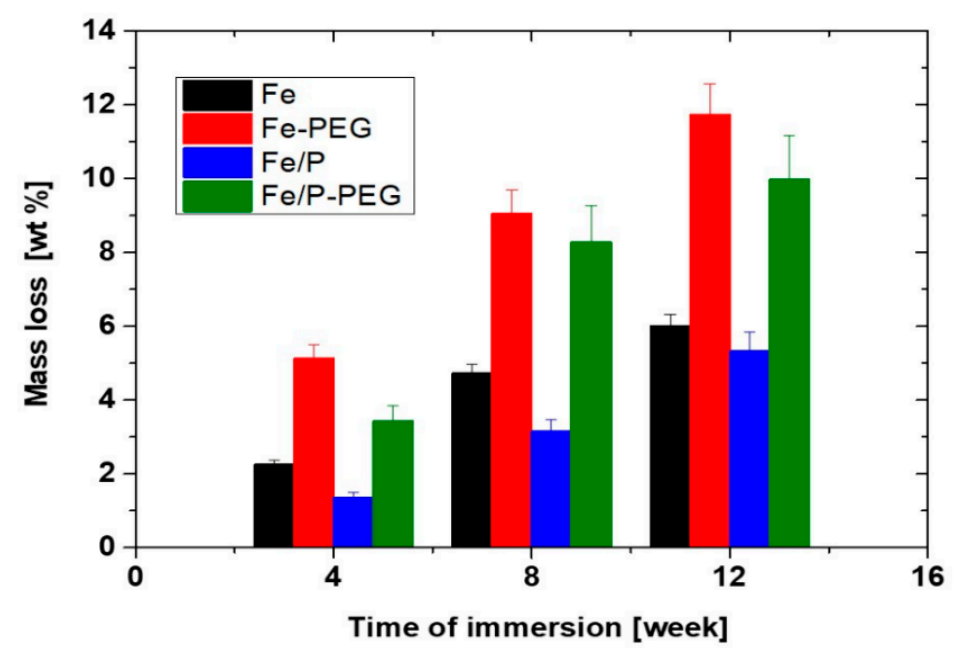

Figure 3. Mass losses during immersion in Hanks' solution for 4, 8, and 12 weeks for iron-based foams (Fe, Fe-PEG, Fe/P, and Fe/P-PEG).

The corrosion rates obtained for iron-based foams in static conditions in Hanks' solution for 4, 8 , and 12 weeks as determined by the mass loss method are presented in Table 3. Phosphating of iron powder caused a slight reduction of corrosion rate of $\mathrm{Fe} / \mathrm{P}$ foam when compared to the bare Fe foam sample. In consistency with the results of our previous research $[25,26,28]$, the higher corrosion rate was observed for samples with a polymer coating layer as compared to foams without PEG. The higher corrosion rate may be due to both the $\mathrm{pH}$ decrease caused by PEG dissolution and degradation and the iron complexation by PEG [28]. The highest corrosion rate was detected for 
the Fe-PEG sample. Changes in CR with time of immersion for samples with polymer were more significant as compared to foams without a PEG coating.

Table 3. The values of corrosion rate $(C R)$ of iron-based foams (Fe, Fe-PEG, Fe/P, and Fe/P-PEG) immersed in Hanks' solution during 4, 8, and 12 weeks.

\begin{tabular}{ccccc}
\hline \multirow{2}{*}{ Time of Immersion (Weeks) } & \multicolumn{4}{c}{$C R\left(\mathbf{m m} \cdot\right.$ Year $\left.^{-1}\right)$} \\
\cline { 2 - 5 } & Fe & Fe-PEG & Fe/P & Fe/P-PEG \\
\hline 4 & $0.0229 \pm 0.0014$ & $0.0492 \pm 0.0020$ & $0.0136 \pm 0.0015$ & $0.0415 \pm 0.0031$ \\
8 & $0.0231 \pm 0.0018$ & $0.0455 \pm 0.0036$ & $0.0131 \pm 0.0021$ & $0.0397 \pm 0.0025$ \\
12 & $0.0222 \pm 0.0017$ & $0.0398 \pm 0.0028$ & $0.0102 \pm 0.0018$ & $0.0364 \pm 0.0022$ \\
\hline
\end{tabular}

\subsection{Electrochemical Corrosion Behavior}

To examine the degradation susceptibility of the foams, the open circuit potentials (OCP) time curves were measured in Hanks' solution (Figure 4a). A decrease of the OCP value was observed for all samples over time. Initial potential values of samples with a PEG coating layer were about $100 \mathrm{mV}$ lower than that of the corresponding samples without a polymeric layer, however the potential drop on the PEG-coated Fe foam was higher than that of the PEG-coated Fe/P sample. This could be related to the appearance of ferric phosphate compounds on the surface of the Fe/P foam sample formed during the phosphating procedure. The phosphating of iron powder and consecutive sintering caused formation of a solidified liquid phase layer consisting of mixed ferric phosphate compounds on the surface of iron powder particles [27,35]. Accordingly, the foam samples manufactured from the phosphated iron powder $(\mathrm{Fe} / \mathrm{P})$ exhibited slightly lower corrosion susceptibility as compared with bare iron materials. After an initial period (0-1500 s), the OCP of all foams reached a nearly steady value.
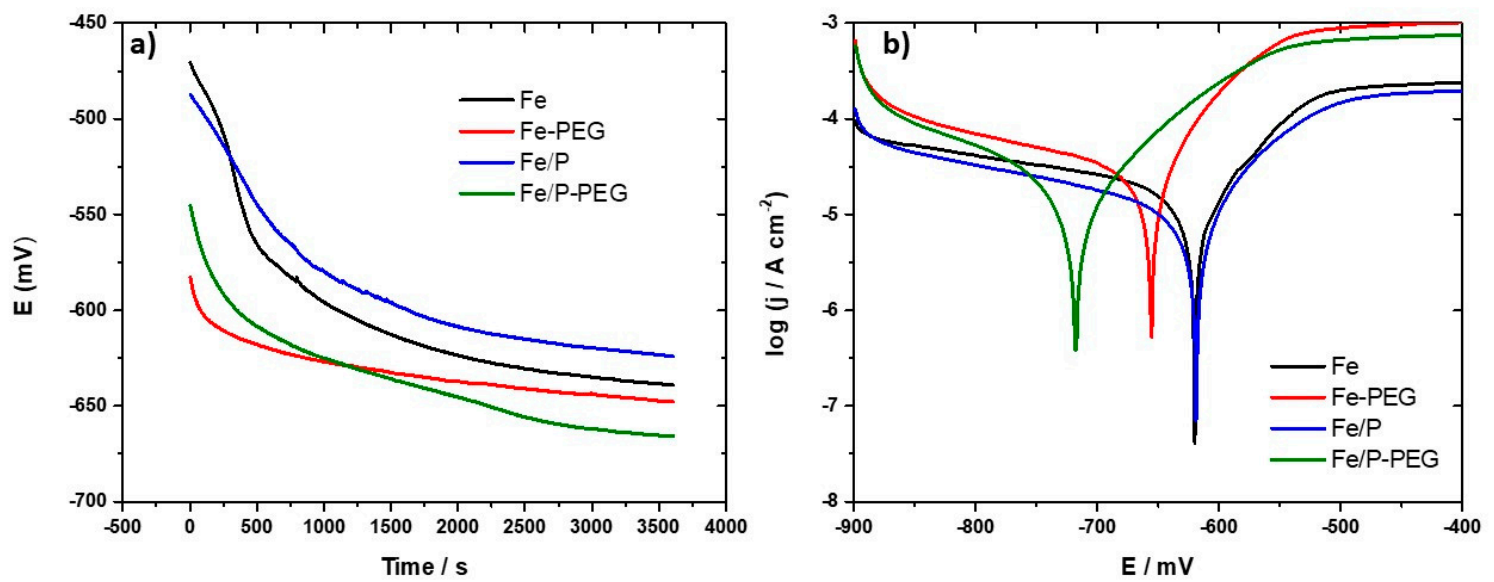

Figure 4. Open circuit potentials (OCP) curves (a) and potentiodynamic polarization curves (b) of iron-based foams (Fe, Fe-PEG, Fe/P, and Fe/P-PEG) in Hanks' solution.

Representative potentiodynamic polarization curves for the foams measured in Hanks' solution (Figure $4 \mathrm{~b}$ ) were used to determine the corrosion potential $\left(E_{\text {corr }}\right)$, corrosion current density $\left(j_{\text {corr }}\right)$, and corrosion rate $(C R)$ (Table 4$)$. 
Table 4. Electrochemical data and corrosion rate $(C R)$ of iron-based foams (Fe, Fe-PEG, Fe/P, and Fe/P-PEG) in Hanks' solution.

\begin{tabular}{cccc}
\hline Sample & $E_{\text {corr }}(\mathbf{m V})$ & $j_{\text {corr }}\left(\boldsymbol{\mu A} \cdot \mathbf{c m}^{-\mathbf{2}}\right)$ & $C R\left(\mathbf{m m} \cdot\right.$ Year $\left.^{-\mathbf{1}}\right)$ \\
\hline Fe & -620 & 16.33 & 0.200 \\
Fe-PEG & -658 & 29.72 & 0.362 \\
Fe/P & -617 & 9.80 & 0.151 \\
Fe/P-PEG & -718 & 18.65 & 0.280 \\
\hline
\end{tabular}

The corrosion potentials of the pure Fe sample and Fe/P sample were similar, while those of Fe-PEG and Fe/P-PEG samples were shifted toward more negative values. This change implied that the polarization takes place predominantly at the cathode and therefore, that the corrosion of foams with PEG coating layers was cathodically controlled [36]. The corrosion current densities and corrosion rates were in the sequence from high to low: Fe-PEG, Fe/P-PEG, Fe, Fe/P. Acceleration of the corrosion of coated samples can be attributed to local acidity in the vicinity of the surface of coated samples caused by the oxidative degradation of PEG $[25,26,28,37]$. A decrease in $\mathrm{pH}$ increases the solubility of the degradation products and thus hinders their precipitation and enables increased oxygen diffusion [18,25]. Moreover, the local acidic environment enhances the reduction of protons at the cathode, resulting in a higher corrosion current density and therefore in higher corrosion rates [38]. Phosphating the iron powder resulted in moderate retardation of the corrosion rate, which was also observed in our previous work [27]. Coating with PEG led to $80 \%$ faster degradation. The degradation of the Fe/P sample was lower but was also increased by $80 \%$ in the coated form.

The results of the electrochemical impedance spectroscopy (EIS) measurements for iron-based foams in Hanks' solution are shown in Figure 5 as Nyquist plots (a) and Bode plots (b).
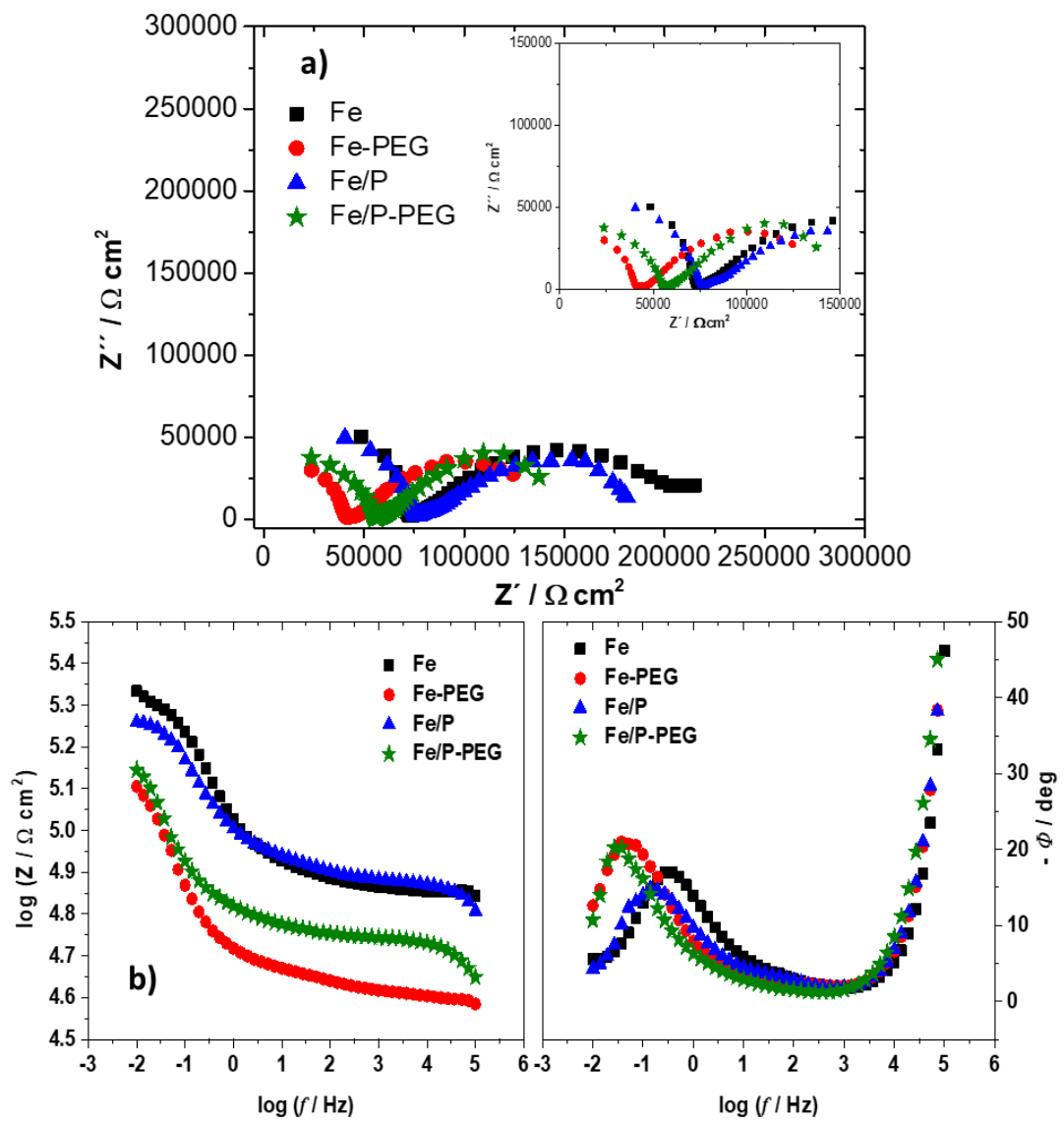

Figure 5. Nyquist diagram (a) and Bode diagram (b) of iron-based foams (Fe, Fe-PEG, Fe/P, and Fe/P-PEG) in Hanks' solution. 
Both an incomplete semi-circle in the high-frequency $(f)$ region and a flattened loop in the low-frequency region in the Nyquist plots corresponded to capacitive behavior. The depressed appearance of capacitive semi-circle in the low-frequency region reflects the surface inhomogeneity and porosity of sintered foams produced by the powder metallurgy method. The diameters of both semi-circles for Fe and Fe/P foams are larger than for Fe-PEG and Fe/P-PEG foams, which indicates the enhancement of the corrosion susceptibility of the samples with the polymeric layer [39].

The Bode plots exhibit one maximum phase lag at the low-frequency region and a second peak of phase lag arises at the high-frequency region for all foams. The time constant observed in the low-frequency region is related to the charge transfer process of the corrosion reaction. The time constant at the high-frequency region is characterized by the presence of a corrosion product film and different kinds of coating. The intermediate frequency region in the Bode diagram describes the change of electrical conductivity after immersion in corrosive medium [40]. A decrease in impedance value $(Z)$ together with the shift of phase shift $(\Phi)$ to lower frequencies was observed for foams after the addition of $P$ or PEG coating as compared to bare Fe foams (Figure $5 b$ ). Values of phase shift were in all cases lower than $-45^{\circ}$ over almost the whole frequency range, implying the non-uniform distribution of current on the foam surface at this region [41]. The phase shift was higher than $-45^{\circ}$ only at the highest frequency limit, referring to uniform current distribution. Accordingly, the undeveloped capacitive semi-circle at the high-frequency region could represent the inhomogeneous current spreading on the surface of porous foam samples [41].

The values of charge transfer resistance $\left(R_{c t}\right)$, which corresponds to the polarization resistance, were calculated for all iron-based foams as the subtraction of the impedance values at lower and higher frequencies [6]. The values of double-layer capacitance $\left(C_{d l}\right)$ that correspond to the difference in local charges between the foam sample and electrolyte were calculated using Equation (5):

$$
C_{d l}=\sqrt{2 \pi f_{\max } R_{c t}}
$$

where $f_{\max }$ is the frequency related to the maximal value of the imaginary impedance component $\left(Z^{\prime}\right)$. The calculated values of $R_{c t}$ and $C_{d l}$ are summarized in Table 5 before and after immersion.

Table 5. Impedance parameters of iron-based foams (Fe, Fe-PEG, Fe/P, and Fe/P-PEG) in Hanks' solution before and after 1-h immersion.

\begin{tabular}{ccccc}
\hline \multirow{2}{*}{ Sample } & \multicolumn{2}{c}{ Before Immersion } & \multicolumn{2}{c}{ After Immersion } \\
\cline { 2 - 5 } & $\boldsymbol{R}_{\boldsymbol{c t}} \mathbf{( \mathbf { k } \boldsymbol { \Omega } \cdot \mathbf { c m } ^ { \mathbf { 2 } } )}$ & $\boldsymbol{C}_{\boldsymbol{d l}}\left(\boldsymbol{\mu \mathrm { F } \cdot \mathbf { c m } ^ { - \mathbf { 1 } } )}\right.$ & $\boldsymbol{R}_{\boldsymbol{c t}} \mathbf{( \mathbf { k } \boldsymbol { \Omega } \cdot \mathbf { c m } ^ { \mathbf { 2 } } )}$ & $\boldsymbol{C}_{\boldsymbol{d l}}\left(\boldsymbol{\mu} \mathbf{F} \cdot \mathbf{c m}^{\mathbf{- 1}}\right)$ \\
\hline $\mathrm{Fe}$ & $146.6 \pm 1.7$ & $530.6 \pm 6.1$ & $232.1 \pm 2.8$ & $671.3 \pm 7.8$ \\
$\mathrm{Fe}-\mathrm{PEG}$ & $89.28 \pm 0.6$ & $155.4 \pm 1.3$ & $117.1 \pm 1.3$ & $153.5 \pm 1.7$ \\
$\mathrm{Fe} / \mathrm{P}$ & $105.5 \pm 1.5$ & $320.3 \pm 4.0$ & $156.8 \pm 1.6$ & $396.7 \pm 5.0$ \\
$\mathrm{Fe} / \mathrm{P}-\mathrm{PEG}$ & $87.91 \pm 0.9$ & $127.4 \pm 1.1$ & $110.3 \pm 1.3$ & $129.0 \pm 1.3$ \\
\hline
\end{tabular}

Values of both resistance and capacitance for samples with the PEG coating layer were markedly lower than that for samples without the polymer layer, which is in accordance with results of OCP measurement and potentiodynamic polarization. The higher $R_{c t}$ values for uncoated $\mathrm{Fe}$ and $\mathrm{Fe} / \mathrm{P}$ foams indicate the formation of a denser passive layer of corrosion products, for example iron oxides, hydroxides, carbonates, and phosphate. The Fe-PEG and Fe/P-PEG foams exhibited lower $C_{d l}$ values compared to those for $\mathrm{Fe}$ and $\mathrm{Fe} / \mathrm{P}$ foams due to higher dissolution of degradation products in the local acidic environment. This indicated the creation of a less coherent, more porous, and permeable passive layer.

The schematic illustration of differences in passive layer density and corrosion behavior due to the polymer layer is depicted in Figure 6. Degradation of Fe and Fe foam samples proceeded in nearly neutral physiological solution, resulting in formation of a dense layer of corrosion products (Figure 6a). A slight inhibition of corrosion rate at the initial stage due to the phosphating was observed 
for Fe/P foam. In case of PEG-coated foams, creation of a less dense and leachier passive layer was observed (Figure $6 \mathrm{~b}$ ) owing to the lower $\mathrm{pH}$ at the metal-solution interface and iron complexation by PEG. This allowed diffusion of oxygen to the iron surface and rapid degradation of foams.

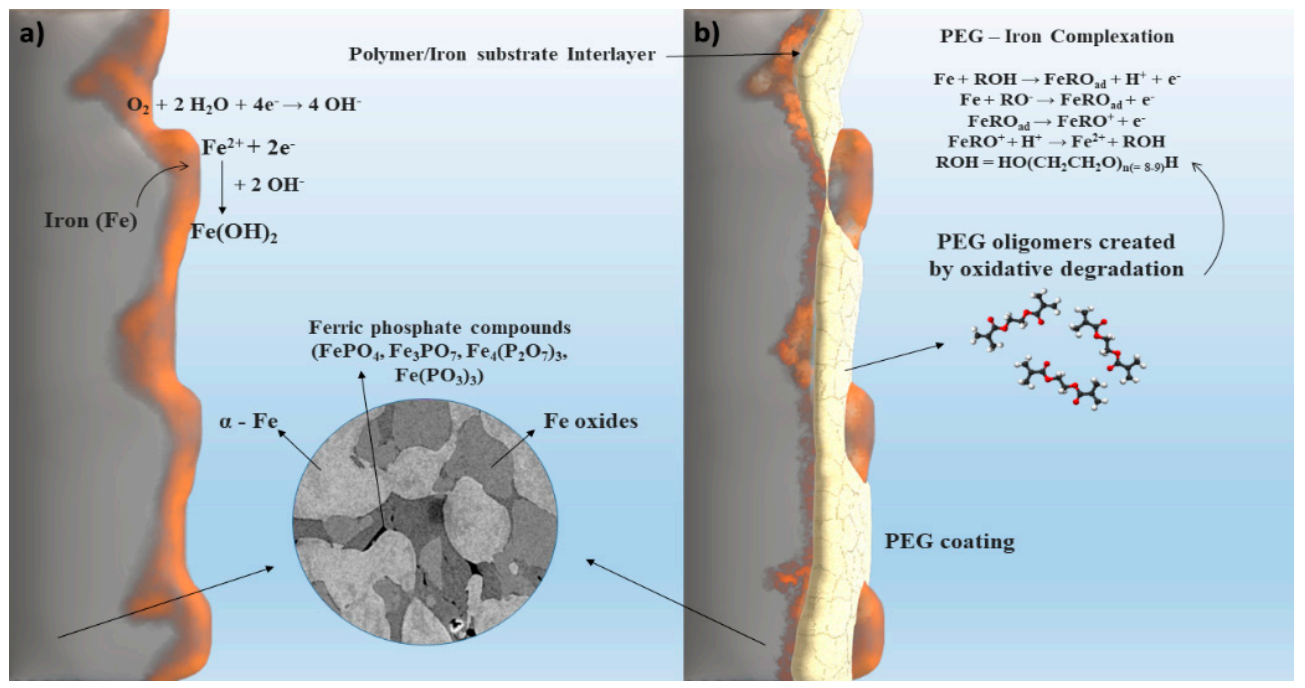

Figure 6. Schematic illustration of differences in passive layer density and corrosion behavior of iron-based foams in Hanks' solution: Fe, Fe/P (a), Fe-PEG, Fe/P-PEG (b).

EIS measurements were also performed after immersion of foams for $1 \mathrm{~h}$ in Hanks' solution (Figure 7). The shapes of the EIS spectra were not changed after exposure in Hanks' solution (Figure 7), suggesting the same mechanism of corrosion, while the diameter of the depressed capacitive semi-circle in the low-frequency region was higher for all foams, indicating the higher resistance, and thus, the lower corrosion rate [38]. The values of $R_{c t}$ and $C_{d l}$ for iron-based foams after immersion were in the same sequence as before immersion. However, the values of $R_{c t}$ after immersion were approximately 1.2-1.5 times higher than before immersion due to the creation of a degradation products layer. The values of $C_{d l}$ remained nearly the same before and after exposure to Hanks' solution, indicating a quasi-steady-state thickness of the adhesive corrosion products layer on the foam sample surface at these conditions.

The foam samples were investigated by FTIR spectroscopy prior to and after immersion in Hanks' solution in order to figure out whether or not the PEG polymer was decomposed. The results are summarized in Figure 8.

The reflections of the polymer were found only in the samples before treatment. This is valid for both Fe-PEG samples (with and without P). The peaks of the polymer were at exactly the same positions as in the case of pure polymer, which is in compliance with the results of our earlier research for the coated iron-based foams with the highest PEG concentration [25]. Moreover, the peak at around $876 \mathrm{~cm}^{-1}$ was also not observed. The individual vibrations corresponding to various functional groups are described by Shameli et al. [42]. After the 1-week immersion in Hanks' solution, no signal was detected, pointing to the complete decomposition of the polymer during the immersion. The absence of polymer layer due to its degradation during immersion in physiological solution led to the creation of a denser film of corrosion products associated with higher resistance, and a lower corrosion rate of the foams after the immersion in Hanks' solution (Table 5, Figure 7). 

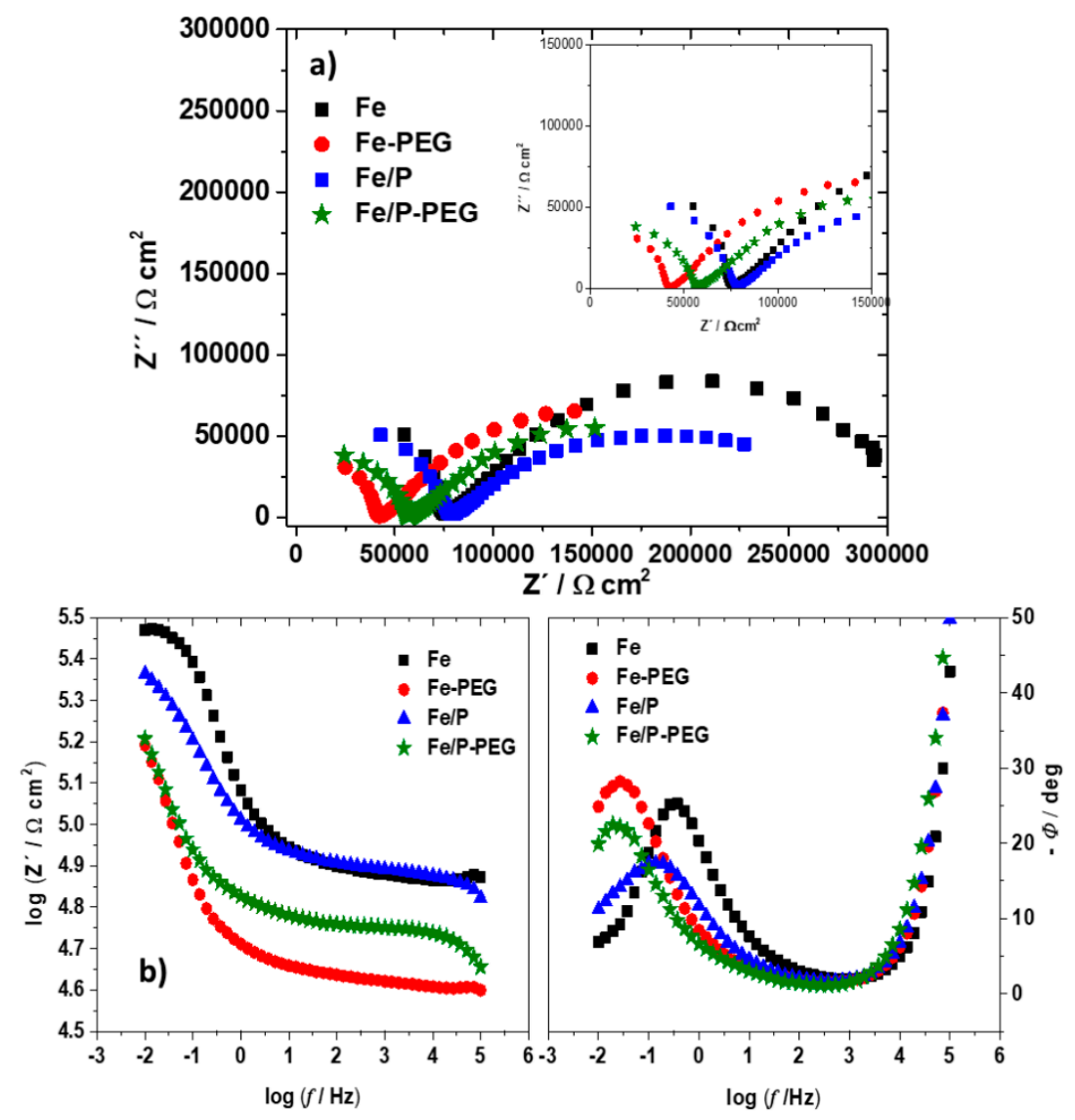

Figure 7. Nyquist diagram (a) and Bode diagram (b) of iron-based foams (Fe, Fe-PEG, Fe/P, and Fe/P-PEG) after $1 \mathrm{~h}$ of immersion in Hanks' solution.

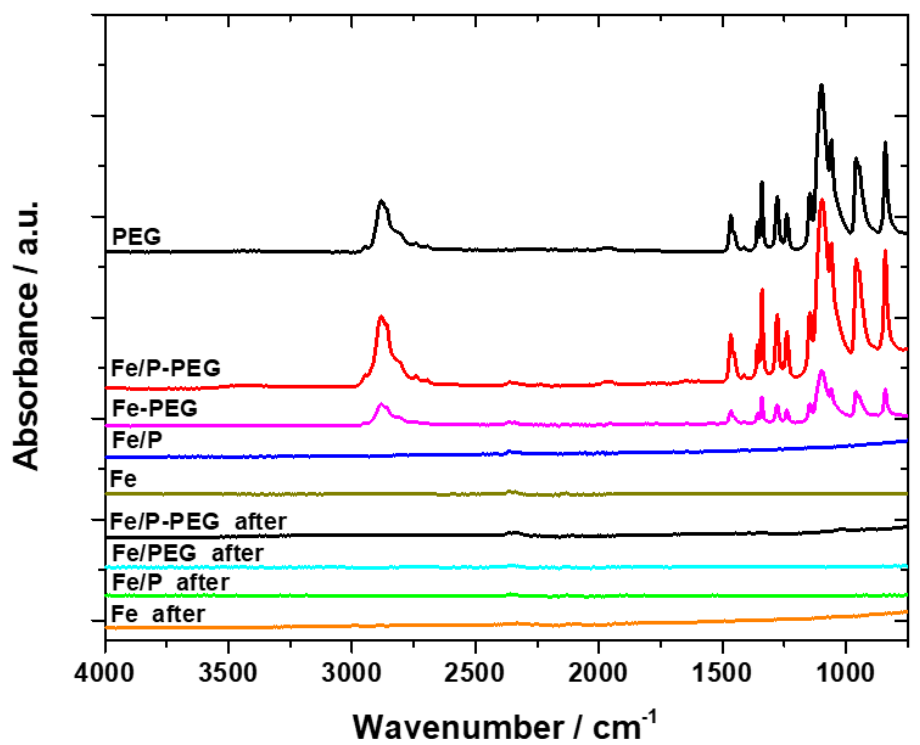

Figure 8. FT-infrared spectra of PEG and iron-based foams (Fe, Fe-PEG, Fe/P, and Fe/P-PEG) before and after 1-week immersion in Hanks' solution.

\section{Conclusions}

Coating of iron-based (Fe and $\mathrm{Fe} / \mathrm{P}$ ) biodegradable materials with a thicker PEG layer than in earlier work was found to produce promising candidates for the design of novel bone substitutes as the 
procedure increased the degradation rate, which represents the main constraint on the application of iron-based biomaterials. It was thought that local acidity caused by the oxidative degradation of PEG hindered the formation of a compact passive film of corrosion products on the iron surfaces and hence increased biodegradation, which was confirmed by a decrease in polarization resistance detected by potentiodynamic polarization and electrochemical impedance spectroscopy. The values of $R_{c t}$ and $C_{d l}$ initially and after $1 \mathrm{~h}$ immersion in Hanks' solution indicated the creation of a more permeable and/or less dense passive layer of degradation products on the surface of coated samples due to the oxidative degradation of PEG. Ions, water, and oxygen could penetrate this layer easier and allow corrosion of the metallic system. The infrared spectroscopy provided proof of the decomposition of PEG during the treatment. The elucidation of the degradation mechanism of these biomaterials in physiological environment demonstrates the possibility of using coating with PEG to control the performance of iron-based degradable biomaterials for healthcare applications.

Author Contributions: Conception, R.O. and A.O.; Data acquisition and analysis, R.G., M.P. (Martina Petráková), Z.O.K., M.K., M.H., M.P. (Mária Podobová), and M.B.; Drafting, R.O.; Revising, R.O., A.O., and R.M.S. Final approval, R.O., and R.M.S. All authors have read and agreed to the published version of the manuscript.

Funding: This work was supported by the Slovak Research and Development Agency (projects APVV-16-0029 and APVV-18-0357), Scientific Grant Agency of the Ministry of Education, Science, Research, and Sport of the Slovak Republic (projects VEGA 1/0074/17 and VEGA 2/0044/18), and Internal Research Grant System of Faculty of Science of Pavol Jozef Šafárik University in Košice (VVGS-pf-2019-1049).

Conflicts of Interest: The authors declare no conflict of interest.

\section{References}

1. Li, H.; Zheng, Y.; Qin, L. Progress of biodegradable metals, Review. Prog. Nat. Sci. Mater. Int. 2014, 24, 414-422. [CrossRef]

2. Purnama, A.; Hermawan, H.; Couet, J.; Mantovani, D. Assessing the biocompatibility of degradable metallic materials: State-of-the-art and focus on the potential of genetic regulation. Acta Biomater. 2015, 6, 1800-1807. [CrossRef] [PubMed]

3. Prakasam, M.; Locs, J.; Salma-Ancane, K.; Loca, D.; Largeteau, A.; Berzina-Cimdina, L. Biodegradable Materials and Metallic Implants-A Review. J. Funct. Biomater. 2017, 8, 44. [CrossRef] [PubMed]

4. Wang, S.; Xu, Y.; Zhou, J.; Li, H.; Chang, J.; Huan, Z. In vitro degradation and surface bioactivity of iron-matrix composites containing silicate-based bioceramic. Bioact. Mater. 2017, 2, 10-18. [CrossRef]

5. Heiden, M.; Walker, E.; Stanciu, L. Magnesium, Iron and Zinc Alloys, the Trifecta of Bioresorbable Orthopaedic and Vascular Implantation-A Review. J. Biotechnol. Biomater. 2015, 5, 1000178.

6. Ulum, M.F.; Arafat, A.; Noviana, D.; Yusop, A.H.; Nasution, A.K.; Kadir, M.A.; Hermawan, H. In vitro and in vivo degradation evaluation of novel iron-bioceramic composites for bone implant applications. Mater. Sci. Eng. C 2014, 36, 336-344. [CrossRef]

7. Hermawan, H. Updates on the research and development of absorbable metals for biomedical applications. Prog. Biomater. 2018, 7, 93-110. [CrossRef]

8. Radha, R.; Sreekanth, D. Insight of magnesium alloys and composites for orthopedic implant applications-A review. J. Magnes. Alloy. 2017, 5, 286-312. [CrossRef]

9. Sharma, P.; Pandey, P.M. Corrosion behaviour of the porous iron scaffold in simulated body fluid for biodegradable implant application. Mater. Sci. Eng. C 2019, 99, 838-852. [CrossRef]

10. Ma, J.; Zhao, N.; Zhu, D. Endothelial Cellular Responses to Biodegradable Metal Zinc. ACS Biomater. Sci. Eng. 2015, 1, 1174-1182. [CrossRef]

11. Yusop, A.H.; Bakir, A.A.; Shaharom, N.A.; Abdul Kadir, M.R.; Hermawan, H. Porous BiodegradableMetals for Hard Tissue Scaffolds: A Review. Int. J. Biomater. 2012, 2012, 641430. [CrossRef]

12. Čapek, J.; Vojtěch, D.; Oborná, A. Microstructural and mechanical properties of biodegradable iron foam prepared by powder metallurgy. Mater. Des. 2015, 83, 468-482. [CrossRef]

13. Sharma, P.; Pandey, P.M.M. Morphological and mechanical characterization of topologically ordered open cell porous iron foam fabricated using 3D printing and pressureless microwave sintering. Mater. Des. 2018, 160,442-454. [CrossRef] 
14. Wegener, B.; Sievers, B.; Utzschneider, S.; Müller, P.; Jansson, V.; Rößler, S.; Quadbeck, P. Microstructure, cytotoxicity and corrosion of powder-metallurgical iron alloys for biodegradable bone replacement materials. Mater. Sci. Eng. B 2011, 176, 1789-1796. [CrossRef]

15. Li, Y.; Zhou, J.; Pavanram, P.; Leeflang, M.A.; Fockaert, L.I.; Pouran, B.; Tümer, N.; Schröder, K.U.; Mol, J.M.C.; Weinans, H.; et al. Additively manufactured biodegradable porous magnesium. Acta Biomater. 2018, 67, 378-392. [CrossRef] [PubMed]

16. Ulum, M.F.; Caesarendra, W.; Alavi, R.; Hermawan, H. In-Vivo Corrosion Characterization and Assessment. Coatings 2019, 9, 282. [CrossRef]

17. Hermawan, H.; Alamdari, H.; Mantovani, D.; Dube, D. Iron-manganese: New class of metallic degradable biomaterials prepared by powder metallurgy. Powder Metall. 2008, 51, 38-45. [CrossRef]

18. Yusop, A.H.M.; Daud, N.M.; Nur, H.; Kadir, M.R.A.; Hermawan, H. Controlling the degradation kinetics of porous iron by poly (lactic-co-glycolic acid) infiltration for use as temporary medical implants. Sci. Rep. 2015, 15, 11194. [CrossRef]

19. Zhou, J.; Yang, Z.; Frank, M.A.; Detsch, R.; Boccaccini, A.R.; Virtanen, S. Accelerated Degradation Behavior and Cytocompatibility of Pure Iron Treated with Sandblasting. ACS Appl. Mater. Interfaces 2016, 8, 26482-26492. [CrossRef]

20. Noviana, D.; Estuningsih, S.; Paramitha, D.; Ulum, M.F.; Hermawan, H. In-vitro Cytotoxicity and In-vivo Tissue Response Study of Foreign Bodies Iron Based Materials. Adv. Mat. Res. 2015, 1112, 449-452. [CrossRef]

21. Cheng, J.; Liu, B.; Wu, Y.H.; Zheng, Y.F. Comparative in vitro Study on Pure Metals (Fe, Mn, Mg, Zn and W) as Biodegradable Metals. J. Mater. Sci. Technol. 2013, 29, 619-627. [CrossRef]

22. Stevens, M.M. Biomaterials for bone tissue engineering. Mater. Today 2008, 11, 18-25. [CrossRef]

23. Lefevre, L.-P.; Banhart, J.; Dunand, D.C. Porous Metals and Metallic Foams: Current Status and Recent Developments. Adv. Eng. Mater. 2008, 10, 775-787. [CrossRef]

24. Su, Y.; Champagne, S.; Trenggono, A.; Tolouei, R.; Mantovani, D.; Hermawan, H. Development and characterization of silver containing calcium phosphate coatings on pure iron foam intended for bone scaffold applications. Mater. Des. 2018, 148, 124-134. [CrossRef]

25. Haverová, L.; Oriňaková, R.; Oriňak, A.; Gorejová, R.; Baláž, M.; Vanýsek, P.; Kupková, M.; Hrubovčáková, M.; Mudroň, P.; Radoňák, J.; et al. An In Vitro Corrosion Study of Open Cell Iron Structures with PEG Coating for Bone Replacement Applications. Metals 2018, 8, 499. [CrossRef]

26. Oriňaková, R.; Gorejová, R.; Macko, J.; Oriňak, A.; Kupková, M.; Hrubovčáková, M.; Ševc, J.; Smith, R.M. Evaluation of In Vitro Biocompatibility of Open Cell Iron Structures with PEG Coating. Appl. Surf. Sci. 2019, 475, 515-518. [CrossRef]

27. Orinakova, R.; Orinak, A.; Giretova, M.; Medvecky, L.; Kupkova, M.; Hrubovcakova, M.; Maskalova, I.; Macko, J.; Kalavsky, F. A study of cytocompatibility and degradation of iron-based biodegradable materials. J. Biomater. Appl. 2016, 30, 1060-1070. [CrossRef]

28. Oriňaková, R.; Gorejová, R.; Orságová Králová, Z.; Haverová, L.; Oriňak, A.; Maskal'ová, I.; Kupková, M.; Džupon, M.; Baláž, M.; Hrubovčáková, M.; et al. Evaluation of mechanical properties and hemocompatibility of open cell iron foams with polyethylene glycol coating. Appl. Surf. Sci. 2020, 505, 144634. [CrossRef]

29. Hrubovčáková, M.; Kupková, M.; Džupon, M. Fe and Fe-P Foam for Biodegradable Bone Replacement Material: Morphology, Corrosion Behaviour, and Mechanical Properties. Adv. Mater. Sci. Eng. 2016, 2016, 6257368. [CrossRef]

30. ASTM G59. Standard Test Method for Conducting Potentiodynamic Polarization Resistance Measurements; ASTM: West Conshohocken, PA, USA, 2009.

31. ASTM G31. Standard Guide for Laboratory Immersion Corrosion Testing of Metals; ASTM: West Conshohocken, PA, USA, 2012.

32. Kou, Y.; Wang, S.; Luo, J.; Sun, K.; Zhang, J.; Tan, Z.; Shi, Q. Thermal analysis and heat capacity study of polyethylene glycol (PEG) phase change materials for thermal energy storage applications. J. Chem. Thermodyn. 2019, 128, 259-274. [CrossRef]

33. Pielichowski, K.; Flejtuch, K. Non-oxidative thermal degradation of poly(ethylene oxide): Kinetic and thermoanalytical study. J. Anal. Appl. Pyrolysis 2005, 73, 131-138. [CrossRef]

34. Han, S.; Kim, C.; Kwon, D. Thermal/oxidative degradation and stabilization of polyethylene glycol. Polymer 1997, 38, 317-323. [CrossRef] 
35. Dudrová, E.; Kabátová, M.; Hvizdoš, P.; Oriňaková, R. Sintered composite materials on the basis of $\mathrm{Fe} / \mathrm{FePO}_{4}$-coated powders. Surf. Interface Anal. 2015, 47, 350-356. [CrossRef]

36. Noor, E.A.; Al-Moubarak, A.H. Corrosion behavior of mild steel in hydrochloric acid solutions. Int. J. Electrochem. Sci. 2008, 3, 806-818.

37. Chen, B.; Evans, J.R.G.; Holding, S. Decomposition of Poly(ethylene glycol) in Nanocomposites. J. Appl. Polym. Sci. 2004, 94, 548-552. [CrossRef]

38. Wu, J.; Lu, X.; Tan, L.; Zhang, B.; Yang, K. Effect of hydrion evolution by polylactic-co-glycolic acid coating on degradation rate of pure iron. J. Biomed. Mater. Res. B 2013, 101, 1222-1232. [CrossRef]

39. Wang, Y.B.; Li, H.F.; Zheng, Y.F.; Li, M. Corrosion performances in simulated body fluids and cytotoxicity evaluation of Fe-based bulk metallic glasses. Mater. Sci. Eng. C 2012, 32, 599-606. [CrossRef]

40. Ribeiro, D.V.; Souza, C.A.C.; Abrantes, J.C.C. Use of Electrochemical Impedance Spectroscopy (EIS) to monitoring the corrosion of reinforced concrete. Ibracon Struct. Mater. J. 2015, 8, 529-546. [CrossRef]

41. Cheng, Q.; Chen, Z. The Cause Analysis of the Incomplete Semi-Circle Observed in High Frequency Region of EIS Obtained from TEL-Covered Pure Copper. Int. J. Electrochem. Sci. 2013, 8, 8282-8290.

42. Shameli, K.; Ahmad, M.B.; Jazayeri, S.D.; Sedaghat, S.; Shabanzadeh, P.; Jahangirian, H.; Mahdavi, M.; Abdollahi, Y. Synthesis and Characterization of Polyethylene Glycol Mediated Silver Nanoparticles by the Green Method. Int. J. Mol. Sci. 2012, 13, 6639-6650. [CrossRef]

(C) 2020 by the authors. Licensee MDPI, Basel, Switzerland. This article is an open access article distributed under the terms and conditions of the Creative Commons Attribution (CC BY) license (http://creativecommons.org/licenses/by/4.0/). 